\title{
BOUNDARY BEHAVIOR FOR SOLUTIONS OF SINGULAR QUASI-LINEAR ELLIPTIC EQUATIONS
}

\author{
JUAN SUN AND ZUODONG YANG
}

Abstract. In this paper, for $1 \leqslant \gamma \leqslant 3$ our main purpose is to consider the quasilinear elliptic equation: $\operatorname{div}\left(|\nabla u|^{m-2} \nabla u\right)+(m-1) u^{-\gamma}=0$ on a bounded smooth domain $\Omega \subset \mathbb{R}^{N}, N>1$. We get some first-order estimates of a nonnegative solution $u$ satisfying $u=0$ on $\partial \Omega$. For $\gamma=1$, we find the estimate: $\lim _{x \rightarrow \partial \Omega} u(x) / p(\delta(x))=1$, where $p(r) \approx r \sqrt[m]{m \log (1 / r)}$ near $r=0, \delta(x)$ denotes the distance from $x$ to $\partial \Omega$. For $1<\gamma \leqslant 3$, we obtain

$$
\lim _{x \rightarrow \partial \Omega} \frac{u(x)}{\left(b_{\gamma} \delta(x)\right)^{\frac{m}{\gamma+(m-1)}}}=1,
$$

where $b_{\gamma}=\frac{\gamma+(m-1)}{m}\left(\frac{m}{\gamma-1}\right)^{\frac{1}{m}}$.

Mathematics subject classification (2010): 35J25, 35J60.

Keywords and phrases: boundary behaviour, quasilinear elliptic equation, singular.

\section{REFERENCES}

[1] L. Andersson And P. T. Chruściel, Solutions of the constraint equation in general relativity satisfying hyperbolic conditions, Dissertationes Matematicae, CCCLV, (1996).

[2] G. Astrita And G. Marrucci, Principles of non-Newtonian fluid mechanics, McGraw-Hill, 1974.

[3] C. BANDLE, Asymptotic behavior of large solutions of quasilinear elliptic problems, ZAMP, 54 (2003), 731-738.

[4] C. BANDLE AND M. ESSÉN, On the solutions of quasilinear elliptic problems with boundary blow-up, Symposia Matematica, 35 (1994), 93-111.

[5] C. BANDLE AND M. MARCUS, Large solutions of semilinear elliptic equations: existence, uniqueness and asymptotic behavior, J. d'Anal. Mathém., 58 (1992), 9-24.

[6] C. BANDLE AND M. MARCUS, Asymptotic behavior of solutions and their derivatives, for semilinear elliptic problems with blowup on the boundary, Ann. Inst. Henri Poincaré, 12 (1995), 155-171.

[7] C. BANDLE AND M. MARCUS, On second order effects in the boundary behavior of large solutions of semilinear elliptic problems, Differential Integral Equ., 11 (1998), 23-34.

[8] S. Berhanu, F. Gladiali, AND G. Porru, Qualitative properties of solutions to elliptic singular problems, J. of Inequal.\& Appl., 3 (1999), 313-330.

[9] S. Berhanu, F. CUCCU, AND G. Porru, On the boundary behavior including second order effects of solutions to singular elliptic problems, Acta Mathematica Sinica, English Series, 23, 3 (2007), 479-486.

[10] M. G. Crandall, P. H. Rabinowitz, And L. Tartar, On a Dirichlet problem with a singular nonlinearity, Comm. Part. Diff. Eq., 2 (1977), 193-222.

[11] F. Cuccu, E. Giarrusso, AND G. PORRU, Boundary behavior for solutions of elliptic singular equations with a gradient term, Nonlinear Analysis, 69, 12 (2008), 4550-4566.

[12] M. DEL Pino AND R. Letelier, The influence of domain geometry in boundary blowup elliptic problems, Nonlinear Anal. TMA., 48 (2002), 897-904.

[13] J. R. Esteban AND J. L. VAZQUEZ, On the equation of turbulent filteration in one-dimensional porous media, Nonlinear Anal., 10 (1982), 1303-1325. 
[14] A. Greco AND G. Porru, Asymptotic estimates and convexity of large solutions to semilinear elliptic equations, Diff. Integral Eqns., 10 (1997), 219-229.

[15] A. S. KALASHNIKOV, On a nonlinear equation appearing in the theory of non-stationary filtration, Trud. Sem. I. G. Petrovski, 1978.

[16] J. B. Keller, On solutions of $\Delta u=f(u)$, Comm. Pure Appl. Math., 10 (1957), 503-510.

[17] A. C. LAZER AND P. J. MCKenna, On a singular nonlinear elliptic boundary value problem, Proc. American. Math. Soc., 111 (1991), 721-730.

[18] A. C. LAZER AND P. J. MCKenNa, Asymptotic behavior of solutions of boundary blow-up problems, Differential integral equations, 7 (1994), 1001-1019.

[19] L. K. MARTINSON AND K. B. PAVLOV, Unsteady shear flows of a conducting fluid with a rheological power law, Magnitnaya Gidrodinamika, 2 (1971), 50-58.

[20] P. J. MCKENNA AND W. REICHEL, Sign-changing solutions to singular second-order boundary value problems, Adv. Differential Equations, 6 (2001), 441-460.

[21] A. NACHMAN AND A. CALlEgARI, A nonlinear singular boundary value problem in the theory of pseudoplastic fluids, SIAM J. Appl. Math., 28 (1986), 271-281.

[22] C. A. StUART, Existence theorems for a class of nonlinear integral equations, Math. Z., 137 (1974), 49-66.

[23] Z. YANG, Non-existence of positive entire solutions for singular and non-singular quasi-linear elliptic equation, J. Comm. Appl. Math., 197 (2006), 355-364. 